\title{
Implementasi Keamanan Kaitanya dengan Peraturan Perundang-Undangan pada Lembaga Pemasyarakatan dan Rumah Tahanan Negara
}

\author{
Galih Ihza Mahendra \\ Politeknik Ilmu Pemasyarakatan \\ Correspondence email : mahlia.audiza51@gmail.com
}

\begin{abstract}
Abstrak. Tujuan penelitian ini adalah untuk mengetahui pengaturan pengamanan pada Lembaga Pemasyarakatan dan Rumah Tahanan Negara terhadap sistem keamanan lembaga pemasyarakatan dan implementasi pengamanan di Lembaga Pemasyarakatan Kuningan. Jenis penelitian deskriptif analisis dengan pendekatan yuridihs empiris. Hasil penelitian mengemukakan bahwa pengaturan Permenkumham No 33 Thn 2015 tentang Pengamanan pada lapas dan rutan Negara telah diatur secara terperinci dan lengkap namun dalam pelaksanaannya terdapat berbagai hambatan sehingga di Lapas Kuningan belum sepenuhnya diterapkan secara maksimal terutama dalam penjagaan dan pengawalan pada saat asimilasi yang seharusnya dilakukan pengawasan dan pengawalam tetapi hanya didampingi oleh staf biasa yang ditugaskan. Kesimpulannya yaitu untuk mengoptimalkan pengamanan memerlukan sumber daya manusia dan sumber daya lainnya seperti teknologi, sarana prasarana.
\end{abstract}

Kata Kunci : Implementasi, Sistem Keamanan, Lembaga Pemasyarakatan.

Abstract. The purpose of this research is to know the security arrangement at Penitentiary Institution and House of Detainee against security system of correctional institution and implementation of security in Penitentiary Kuningan. This type of descriptive analysis research with empirical juridical approach. The result of the research stated that the Regulation of Permenkumham Number 33 Year 2015 concerning Security at Penitentiary and House of Detainees has been arranged in detail and complete but in its implementation there are various obstacles so that in Kuningan has not fully applied maximally, especially in guarding and guarding at the time of assimilation which should be supervised and supervised but only accompanied by regular staff assigned. The conclusion is that to optimize security requires human resources and other resources such as technology, infrastructure.

\section{Keywords: Implementation, Security System, Correctional institution}

\section{PENDAHULUAN}

Sistem pemasyarakatan bisa disebut sebagai proses pembinaan bagi para WBP yang berdasarkan pada pancasila. Sistem tersebut dilaksanakan oleh pembina yang ada pada lembaga permasyarakatan, warga binaan permasyarakatan, serta masyarakat sekitar sebagai tindakan dalam meningkatkan mutu dan kualitas hidup bagi warga binaan pemasyarakatan sehingga mereka bisa menginstrospeksi diri. Sehingga dapat menjadi manusia yang lebih baik dan dapat diterima kembali oleh lingkungan masyarakat. Selain itu, saat berada di dalam lembaga permasyarakatan seorang narapidana tetap mendapatkan jaminan atas hak-haknya tatas jaminan rasa aman di lembaga pemasyarakatan. Hal tersebut sesuai berdasarkan sistem permasyarakatan yang ada pada lembaga permasyarakatan tersebut.

Menurut KBBI atau yan dikenal sebagai buku besar Bahasa Indonesia, narapidana ialah orang hukuman (orang yang sedang menjalani masa hukumannya karena tindak pidana). ${ }^{1}$ kaitanya dengan hal ini, Simontakir mengartikan narapidana sebagai orang yang di tahanan, orang yang ditahan pada Lembaga Pemasyarakatan. ${ }^{2}$ Berdasarkan pengertian tersebut dapat diartikan bahwa Narapidana merupakan terpidana yang menjalani hukuman atas tindakan kriminal dilakukan, yang berakibat mereka tidak memiliki kebebasan seperti masyarakat diluar. Meskipun demikian, hal tersebut tidak menghambat kepentingan hukum dari orang-orang yang berkedudukan sebagai terpidana.

Seorang narapidana meskipun telah kehilangan kebebasannya selama berada di dalam lembaga pemasyarakatan, hak- hak yang mereka miliki sebagai seorang warga negara telah dijamin oleh negara berdasarkan pada UUD RI thn 1945 Pasal 28G ayat (1).

Dalam Pasal 8 UU No 39 Thn 1999 mengenai Hak Asasi Manusia dikatakan yakni : "Pemajuan, perlindungan, penegakan dan pemenuhan HAM menjadi tanggung jawabnya pemerintah". Sesuai pasal tersebut diharapkan bagi seorang napi bisa kembali ditengah-tengah masyarakat dan dapat kembali dalam kehdupan bersosial. Sesuai dengan tujuan pemerintah dalam pemenuhan HAM, proses pelaksanaan serta pemenuhan HAM bagi narapidana harus

\footnotetext{
${ }^{1}$ Pusat Bahasa Depdiknas, KaMUS Besar Bahasa Indonesia, PT. Gramedia Pustaka, Jakarta, 2008 , hlm. 683.

${ }^{2}$ J.T.C. Simontakir dkk, KaMUs HUKUM, Sinar Grafika, Jakarta, 2003, hlm. 102.
} 
dijalankan semestinya, pada dasarnya seorang napi juga bukan hanya untuk sebagai objek pembinaan saja akan tetapi juga sebagai subjek pembinaan agar bisa dikembalikan kepada masyarakat.

Menurut PERMEN KUMHAM RI No 33 Thn 2015 "Pengamanan pada Lapas dan rutan". menjelaskan bahwa pada menyelenggarakan pengamanan pada Lembaga pemasyaraktan dan Rumah tahanan dapat dibentuk satuan tugas kamtip dengan klasifikasi pengamanan didasarkan pada pola bangunan dan pengawasan. Pelaksanaan pengamanan meliputi kegiatan pencegahan, penindakan, dan pemulihan.

Namun fakta di lapangan menunjukkan bahwa PERMEN KUMHAM RI No 33 Thn 2015 belum sepenuhnya dapat diterapkan secara baik dengan. Hal ini sebagaimana terjadi di lapas Klas IIA Kuningan yang belum melakukan pengawalan dengan baik terhadap narapidana khususnya pada saat cuti mengunjungi keluarga, asimilasi, dan proses peradilan. Munculnya masalah tersebut dikarenakan masih kurangnya tenaga petugas keamanan di Lapas Klas IIA Kuningan.

\section{METODE PENELITIAN}

Penelitian yang digunakan bersifat deskriptik- analitik, yaitu menerangkan secara rinci bagaimana implementasi Permenkumham No 33 Thn 2015 "Pengamanan pada Lapas dan Rutan Negara terhdap sistem keamanan pada Lembaga Pemasyarakatan", dimana untuk selanjutnya dianalisa dengan menggunakan pendekatan yuridis empiris. Sumber data berasal dari pustaka dan fakta yang ada dilapangan. Pendekatan yuridis empiris ini bertujuan agar mengetahui landasan dari metodologis operasional yang dipakai pada lapas dalam penerapkan sistem keamanan dalam lembaga pemasyarakatan sehingga dapat diketahui sejauh mana implementasi Permenkumham No33 Thn 2015 tentang Pengamanan pada LApasdan Rutan Negara terhadap sistem keamanan pada Lembaga Pemasyarakatan.

Penelitian seperti ini juga sering disebut sebagai penelitian kepustakaan, yaitu prosedur untuk mengumpulkan data yang bersumber dari literatur atau bahan literatur, perundang-undangan terkait, tulisan atau penelitian hukum. Pendekatan dalam penelitian ini adalah kualitatif dengan berorientasi pada pengembangan narasi dan / atau deskripsi tekstual dari fenomena yang diteliti. Sumber data utama penelitian ini adalah studi literatur, yaitu dengan mengamati, mempelajari, membaca materi hukum dan keputusan serta dokumen yang terkait dengan penelitian ini.

\section{HASIL DAN PEMBAHASAN}

Menurut pada teori, hukum menjadi sebagai alat pembentuk dalam merubah masyarakat (Law as Tool Social Engineering). Teori tersebut dijalankan pada Lembaga Pemasyarakatan yaitu dengan pemberian pembinaan terhadap warga binaan permasyarakatan atau narapidana. Sebelum adanya konsep tersebut, keadaan di dalam penjara seringkali menjadi tempat yang menyeramkan karena sering adanya tindak kekerasan yang dilakukan oleh sesama terpidana. Tujuan dari adanya sistem pemasyarakatan adalah untuk mengubah pola tingkah laku dari narapidana menjadi manusia yang lebih baik, sehingga saat mereka lulus dari lapas kehadiran mereka bisa diterima oleh kalangan masyarakat dan mampu menjadi warga negara seperti pada umumnya.

Hukum menurut konsepsi Mochtar Kusumaatmaja yang dikutip oleh Juhaya Praja dalam ciptaannya mengenai Teori Hukum yang dibuat dan pengaplikasinya mengartikan bahwa hukum itu tidak hanya seperangkat kaidah dan asas yang mengatur pada kehidupan manusia dalam masyarakat, tetapi juga harus mencakup samapi kelembaga (institUtion) dan proses (processes) yang mana diperlukannya untuk mewujudkan hukum itu kedalam lingkungan masyarakat. ${ }^{3}$

Selain itu Pengaturan Permenkumham mengenai Pengamanan pada Lapas dan Rutan Negara menjelaskan bahwa apa yang dimaksud dengan gangguan kamtip adalah suatu situasi kondisi yang menimbulkan keresahan, ketidakamanan, serta ketidaktertiban kehidupan di dalam Lapas atau Rutan. Pengamanan merupakan segala bentuk kegiatan dalam rangka melakukan pencegahan, penindakan dan pemulihan terhadap setiap gangguan keamanan dan ketertiban di Lapas atau Rutan.

Dari Permenkumham Nomor 33 Tahun 2015 penyelenggarakan pengamanan di lembaga pemasyarakatan dibentuk satuan tugas Kamtip yang mana diemban oleh DIRJEN PAS untuk satuan tugas kamtip setingkat pusat, dan KAKAWINLI KEMENKUMHAM RI. Untuk satuan tugas kamtipdi tingkat wilayah provinsi, ketentuan lainnya dijelaskan sebagaimana uraian sebagai berikut:

Pengamanan yang dilakuan berdasarkan klasifikasi yang telah ditentukan: pengamanan dengan tingkat sangat tinggi, pengamanan tingkat tinggi, pengamanan sedang, dan pengamanan terrendah. Klasifikasi pengamanan tersebut didasarkan pada pola bangunan dan pengawasan. Pelaksanaan klasifikasi pengamanan meliputi beberapa hal yaitu:

${ }^{3}$ Juhaya S. Praja, Teori HUKUM dan Aplikasinya, CV. Pustaka Setia, Bandung, 2011, halaman 26. 
1. Pengamanan tingkat sangat tinggi dilengkapi dengan adanya pemagaran berlapis, terdapat pos menara yang berada diatas, termasuk juga pos bawah, penempatannya yang sudah terpisah, pengawasan secara closed circUIt television, pembatasan geraksudah diterapkan, pembatasan kunjungan dan pembatasan kegiatan pembinaan, serta pengendalian komunikasi.

2. Pengamanan tingkat tinggi dilengkapi dengan pemagaran berlapis, pos menara atas penempatan terpisah atau bersama, pengawasan closed circUIt television, pembatasan gerak, pembatasan kunjungan, dan kegiatan pembinaan.

3. Pengamanan sedang sudah dilengkapi dengan pemagaran minimal 1 (satu) lapis, penempatannya sudah terpisah atau bersama, pengawasannya secara closed circUIt television, terdapat pembatasan kunjungan dan pembatasan kegiatan pembinaan.

4. Pengamanan tingkat rendah tanpa menggunakan pagar yang berlapis, penempatannya yang terpisah dan bersama, pengawasan closed circUit television dan pembatasan kegiatan pembinaan.

Dalam Penyelenggaraan pengamanan terhadap narapidana mencakup beberapa kegiatan diantaranya pencegahan, penindakan, dan pemulihan. Upaya dalam mencegah terjadinya gangguan keamanan dan ketertiban pada Lapas atau Rutan, yakni:

1. Memeriksa pada setiap keluar dan Masuk pintu, Pemeriksaan ini ialah pemeriksaan pada administrasi yang dikerjakan terhdap seseorang yang hendak akan masuk kehalaman Lapas atau Rutan. Pemeriksaan dilakukan oleh Satuan Pengamanan.

2. Penjagaan dikerjakan di beberapa pintu yaitu: gerbang pintu halaman, pengamanan pintu utama, ruangan kunjungan, lingkungan blok hunian, blok-blok hunian, pos atas, dan area lainnya yang sudah ditetapkan oleh Kepala Lapas atau Rutan. Penjagaan dilakukan oleh Regu Pengamanan.

3. Pengawalan diberikan terhadap napi atau tahanan pada saat hendak keluar seperti: izin luar biasa, CMK, CMB, CB proses peradilan, asimilasi, pemidanaanp, perawatan medis di luar Lapas maupun Rutan, serta kebutuhan lainnya sesuai dengan ketentuan perundang- undangan. Pengawalan diberikan oleh Satuan Pengamanan atas izin dari KaLapas atau KaRutan.

4. Penggeledahan, yakni: penggeledahan pada bagian badan, penggeledahan pada barang bawaan, penggeledahan sel, penggeledahan area, penggeledahan kendaraan. Pemeriksaan ini dilakukan oleh: petugas dari Satuan Pengamanan dan petugas yang telah dierikan amanah, anggota Kamtip dari Divisi Pemasyarakatan pada KANWIL KEMENKUMHAM, atau petugas satuan tugas Kamtip dari Dirjen pas.

5. Inspeksi terhadap plaksanaan prosedur kengamanan diLapas atau diRutan. Inspeksi yang dilakukan secara insidentil oleh para petugas PAS yang dipilih oleh KaLapas atau kaRutan.

6. Melakukan pengendalian control pada beberapa askses yang ada seperti: gerbang pintu halaman, gerbang pintu utama, pengamanan pintu utama, ruangan kunjungan, lingkungan blok, blok-blok hunian, menara atas, pagar dalam dan pagar luar, kantor, steril area, dan pengamanan area lainnya yang ditetapkan oleh Kepala Lapas atau Rutan. Kontrol dilakukan secara intensif oleh Kepala pengamanan atau Wakil Kepala Regu bagian Pengamanan.

7. Melakukan giat Intelijen, yang dilakukan guna mendukung kegiatan pengamanan di lingkungan Lapas ataupun Rutan terhadap potensi yang akan timbul dari gangguan kamtip. Kegiatan intelijen ini meliputi antara lain pengelolaan, pengumpulan, dan pertukaran informasi. Kegiatan ini dilakukan oleh para pejabat yang diberi amanah oleh Dirjen pas, Divisi Pemasyarakatan, dan Lapas atau Rutan.

8. Pengendalian Peralatan, dijalankan dengan mengelola seluruh sarana pengamanan dan sarana lain yang dapat menyebabkan timbulnya gangguan keamanan dan ketertiban. Sarana pengamanan meliputi: senpi, perlengkapan anti huru hara, kunci dan gembok blok hunia, alat komunikasi, ruangan kendali, alat damkar dan kendaraan. Sarana lainnya antara lain yaitu: alat-alat perkantoran, peralatan bengker, alat kelolah dapur, dan peralatanperalatan kebersihan. Pengendalian sarana pengamanan dilakukan oleh Kepala Satuan Pengamanan. Pengendalian sarana lain dilakukan oleh petugas pada bagiannya masing-masing dan melaporkan hasil pengendalian kepada Kepala Satuan Pengamanan.

9. Pengawasan melalui Komunikasi, untuk mengawasi, meneliti, mencatat, dan memberikan batas kegiatan komunikasi bagi napi dan tahanan dengan dunia luar lapas. Pengawasan ini dilakukan oleh bagian Pengamanan.

10. Pengendalian/pengawasan pada Lingkungan, dilakukan aagar memastikan lingkungan aman dan tertip serta steril area. Pengendalian/pengawasan lingkungan yang diterapkan di kawasan steril area ini dilakukan untuk melarang para napi untuk melakukan atau kegiatan lain tanpa izin dari Ka.Lapas dan Ka.Rutan. Pengendalian/pengawasan lingkungan di kawasan jalan orang sebagaimana yang diberikan dengan memberi batas gerak mereka, serta memberikan batas area kepada kegiatan napi dan tahanan. Pengendalian/pengawasa lingkungan dilakukan oleh petugas bagianPengamanan. 
11. Penguncian, diberikan agar menjaga keamanan dan ketertiban didalam Lapas atau Rutan. Penguncian diberikan kepada: gerbang halaman, gerbang utama, Pengamanan pintu utama, kamar-kamar hunian, lingkungan blok-blok hunian, dan ruangan perkantor. Penguncian dilakukan oleh Regu Pengamanan.

12. Penempatan dalam Rangka Pengamanan, dimaksudkan untuk mencegah gangguan keamanan dan ketertiban yang meliputi: pelanggaran disiplin, pelarian, terancam jiwanya, membahayakan jiwa orang lain, memiliki potensi mengembangkan jaringan kejahatan, dan mengancam stabilitas keamanan negara. Penempatan dilakukan pada; strapsel, isolasi, dan blok hunian khusus napi yang melakukan pelanggaran. Bagian ini dilakukan oleh regu Pengamanan dengan izin dari KaLapas dan KaRutan.

13. Investigasi dan Reka Ulang, dilakukan untuk memperoleh alasan serta sebab terjadinya gangguan Kamtip. Investigasi dan reka ulang dilakukan oleh petugas pemasyarakatan

14. Tindakan Lainnya yaitu Sesuai dengan Peraturan Perundang-Undangan, Tindakan lain terkait pencegahan gangguan keamanan dan ketertiban pada Lapas atau Rutan.

Penindakan yang diberikan untuk memberhentikan dan meminimalkan serta melokalisir gangguan kamtip. Penindakan ini terjadi jikalua: terdapat kerusuhan perorangan maupun secara massal, penyerangan kepada petugas, percobaan untuk melakukan pelarian, pelarian, rencana bunuh diri, bunuh diri, keracunan secara besar besaran atau terjangkit penyakit, dan pelanggaran lain yang dilakukan. Dalam melakukan penindakan, petugas Lapas atau Rutan wajib menggunakan kekuatan yang berkelanjutan. Penggunaan kekuatan yang berkelanjutan meliputi beberapa hal yaitu:

1. Kehadiran petugas Lapas atau Rutan dimaksudkan agar penindakan ini dilakukan dengan mengutamakan pendekatan persuasif sehingga pada saat berhadapan dengan narapidana atau tahanan merasa lebih aman.

2. Perintah ucapan bertujuan agar penindakan yang diberikan dapat memberikan perintah yang jelas serta dapat diperhitungkan dengan baik pada saat berhadapan dengan napi atau tahanan yang menolak pada saat diajak unutk bekerja sama.

3. Kekuatan fisik dengan Teknik yang ringan bertujuan untuk penindakan serta memecah belah kekuatan narapidana atau tahanan dan pembatasan gerak fisik pada saat berhadapan dengan narapidana atau tahanan.

4. Kekuatan fisik dengan teknik yang sedikit keras dan melumpuhkan bertujuan agar tingkat pada tindakan dengan menggunakan tindakan fisik bertujuan untuk menjatuhkan dan menyerang saat berhadapan dengan narapidana atau tahanan yang melakukan perlawanan.

5. Kekuatan dengan Teknik yang dapat mematikan bertujuan untuk penindakan saat berhadapan dengan napi atau tahanan yang membahayakan keselamatan, dilakukan dengan: memberi pukulan ke bagian atau daerah yang sangat vital dan menggunakan senjata api.

Bantuan dari regu pengamanan terdiri dari: bantuan pengamanan dari dalam dan bantuan pengamanan luar. Bantuan pengamanan dalam dibutuhkan ketika pihak upt kekurangan petugas pengamanan. KaLapas atau KaRutan memberikan jabatan fungsional umum kpda petugas bantuan pengamanan internal. Bantuan pengamanan dari dalam berada di bawah perintah dari Komandan Regu Pengamanan.

\section{Implementasi Permenkumham Nomor 33 Tahun 2015 di Lembaga pemasyarakatan Kuningan}

Di dalam Lembaga Pemayarakatan Kuningan pada implementasinya seringkali terjadi berbagai macam gangguan diantaranya baik gangguan keamanan maupun ketertiban. Jenis gangguan yang paling sering terjadi di adalah kerusuhan antara sesama narapidana maupun pelarian yang dilakukan oleh narapidana. Sebagai upaya dalam penanggani hal tersebut, bagi narapidana yang melakukan akan dimintai keterangan kenapa kerusuhan tersebut bisa terjadi kemudian akan diberikan sanksi dan kemudian diasingkan sementara.

Cara penerapan pada pelaksanaan keamanan bagi napi di Lembaga Pemasyarakatan Kuningan umumnya yaitu: penjagaan, pengawasan, dan pengawalan. Cara yang diterapkan dalam pelaksanaan keamanan bagi narapidana dijelaskan bahwa perlindungan yang diterapkan dalam pelaksanaan keamanan bagi napi yaitu dilakukannya Protap atau Prosedur Tetap oleh setiap penjaga atau setiap petugas keamanan. ${ }^{4}$

Selanjutnya penjagaan di Lembaga Pemasyarakatan Kuningan terdiri dari beberapa pos yaitu: 6 pos menara atas, blok I, dan blok II. Untuk pos menara atas yang diisi hanya satu pos menara oleh 1 orang penjaga yaitu pos menara II, sedangkan untuk setiap blok masing-masing terdiri dari 1 orang penjaga. Penjagaan dilakukan pula pada pintu blok II oleh 1 orang penjaga. Pengamanan pintu utama dipimpin oleh 1 orang penjaga. Pengamanan tersebut dilakukan melalui empat regu yang terdiri dari 6 orang termasuk 1 orang komandan. Pengamanan shift malam untuk regu pengamanan dibantu oleh 1 orang petugas piket malam yang ditunjuk dari petugas staf oleh Kalapas dan diawasi oleh Pengawas Umum (PU) yang ditunjuk dari Pejabat Eselon III oleh Kalapas. Pengamanan di hari libur nasional diawasi oleh Wasin (Pengawas Intern) yang ditunjuk dari Pejabat Eselon III oleh Kalapas. 
Situasi keamanan pada napi di Lembaga Pemasyarakatan Kuningan relatif baik. Pegawai rugu keamanan memberikan pengawasan dan penjagaan terhdap napi dengan memberikan laporan perhari dan berita acara mengenai pelaksanaan pembinaan serta memberikan keterangan kondisi keamanan di Lembaga Pemasyarakatan Kuningan adalah baik.

Terkait dengan implementasi terhadap Permenkumham Nomor 33 Tahun 2015, Kepala Kesatuan Pengamanan Lembaga Pemasyarakatan dikuningan menjelaskan bahwa pada umumnya pencegahan gangguan kamtip di Lembaga Pemasyarakatan Kuningan sudah dilaksanakan dengan baik khususnya berkaitan dengan pemeriksaan pada pintu keluar masuk orang, penggeledahan, inpeksi, kegiatan intelijen, pengendalian peralatan, pengawasan komunikasi, pengendalian lingkungan, serta tempat dalam rangka pengamanan, dan investigasi pada reka ulang. Namun berkaitan dengan penjagaan terdapat kendala berupa belum diisinya semua pos menara atas oleh penjaga dimana yang diisi hanya 1 pos menara atas yaitu pos menara II. Selain itu, pengawalan pada saat asimilasi tidak dilakukan oleh Satuan Pengamanan dilakukan oleh petugas yang dipilih langsung oleh Kalapas. Dengan demikian dapat dinyatakan bahwa pengoprasian terhadap Permenkumham No 33 Thn 2015 di Lembaga Pemasyarakatan Kuningan belum dilakukan sepenuhnya secara maksimal.

Sebagai langkah pengoptimalan pengamanan pada Lapas Kuningan, petugas dari regu pengaman lapas memiliki waktu untuk rolling dan berkeliling. Kegiatan tersebut dilakukan setiap hari oleh petugas keamanan setelah melakukan apel pagi, dengan berkeliling area kompleks lapas. Selain itu, juga dapat meminimalkan resiko terbentuknya kecurangan maupun masuknya barang-barang terlarang, kunjungan yang dilakukan oleh setiap keluarga atau kerabat harus melalui tahap pemeriksaan. Tahapan tersebut dilakukan mulai dari pemeriksaan pakaian, maupun pemeriksaan terhdap barang bawaan. Pengaturan keamanan tersebut sebagai bentuk meningkatkan mutu dari lembaga pemasyarakatan sehingga dapat berjalannya pembinaan dan bimbingan kepada warga binaannya dengan baik, dan dapat memberikan keamanan bagi narapidana dan petugas Lapas.

Mengenai hambatan apa saja yang terjadi di Lembaga Pemasyarakatan Kuningan dalam melakukan keamanan untuk para narapidana terdapat hambatan anatarnya yakni kurangnya petugas keamanan Lembaga Pemasyarakatan Kuningan. KPLP Kuningan, berkata jumlah petugas keamanan di Lembaga Pemasyarakatan ini tidak setara dengan para narapidana yang ada ${ }^{5}$. Berdasarkan fakta yang ada dilapangan jumlah napi adalah 417 orang, sedangkan petugas keamanan hanya berjumlah 24 orang, itupun terbagi-bagi menjadi beberapa shiff yang telah ditetapkan. ${ }^{6}$

Berdasarkan pada fakta data dilapangan dapat disimpulkan bahwa jumlah petugas tidak seimbang dengan narapidana yang ada. Hal tersebut bisa saja dapat menimbulkan adanya gangguan terhadap para warga binaan permasyarakatan atau narapidana maupun terhadap petugas lapas. Selain itu perlunya penambahan jumlah personil petugas keamanan serta melakukan pelatihan-pelatihan sesuai dengan kemapuan dan keahlian yang dimilki untuk meningkatkan SDM para petugas bagian keamanan pada Lapas. Hal ini juga sebagai upaya agar tidak terjadi hal yang tidak dinginkan. Perlunya adanya pembatasan interaksi antara narapidana dengan orang dilingkungan luar, agar ruang bergerak para napi sangat terbatas, sehingga nantinya akan sulit bagi mereka melarikan diri. Solusi dalam peningkatan dari segi keamanan di Lembaga Pemasyarakatan Kuningan juga diterapkannya dengan sistem personal atau pendekatan perseusif, dikarenakan akan muncul rasa kekeluargaan antara narapidana jadi akan mudah untuk diberikan arahan, tanpa harus mengurangi rasa patuh narapidana kepada petugas (Lapas), pengamanan bukan lagi dengan dilakukan dengan ancaman atau kekerasan.

Implementasi Permenkumham Nomor 33 Tahun 2015 di Lembaga Pemasyarakatan Kuningan faktanya belum terlakasana secara maksimal. Maka diperlukan adanya pemaksmimalan penerapan peraturan perundang-undangan ini dari segi SDM maupun sarpras untuk menunjang. Selain itu pengamanan pada lapas harus dilakukan secara maksimal baik secara internal maupun eksternal. Apabila semua sudah berjalan secara maksimal, upaya pembinaan terhadap wwarga binaan permasyarakatan atau narapidana akan mampu berjalan sesuai tujuan.

Fakta lain dari penerapan PERMENKUMHAM RI No 33 Thn 2015 yang terjadi di Lembaga Pemasyarakatan Kelas IIA Kuningan menunjukkan bahwa belum sepenuhnya dapat diimplementasikan dengan baik. Hal ini ditunjukkan dengan belum dilakukannya pengawalan dengan baik terhadap narapidana khususnya pada saat cuti mengunjungi keluarga, asimilasi, dan proses peradilan. Hal tersebut juga didasari karena adanya kurangan tenaga petugas keamanan di Lembaga Pemasyarakatan Kuningan. terdapat Pengaturan Permenkumham mengenai Pengamanan pada lapas dan Rutan Negara PERMENKUMHAM Nomor 33 Tahun 2015 dimaksud untuk tindakan pencegahan dan penanggulangan gangguan kamtip yang ada pada lapas yang berakibat pada terjadinya tindak ketidakamanan, serta ketidaktertiban di dalam Lapas atau Rutan.

\footnotetext{
${ }^{5}$ wawancara dengan Kepala Kesatuan Pengamanan Lembaga Pemasyarakatan Kelas IIA Kuningan

${ }^{6}$ Ibid.
} 
Galih Ihza Mahendra, Implementasi Keamanan Kaitanya dengan Peraturan Perundang-Undangan pada Lembaga

\section{SIMPULAN}

Menurut penguraian diatas penulis dapat memberikan kesimpulan bahwa Permenkumham No 33 Tahun 2015 ini terhadap Sistem Keamanan Lembaga Pemasyarakatan dilaksanakan melalui klasifikasi yaitu: pengamanan yang amat sangat tinggi, pengamanan tinggi, pengamanan sedang, dan pengamanan tingkatan terrendah. Pencegahan gangguan kamtip ini terjadi pada Lapas atau Rutan, meliputi: pemeriksaan pintu keluar dan masuk, pengawalan,control, penjagaan, penggeledahan, inpeksi,, kegiatan intelijen, peralatan pengendalian, pengawasan dari segi komunikasi, pengendalian pada segi lingkungan, pengamanan pada penguncian blok blok hunia, penempatan narapidana dalam rangka pengamanan, investigasi dan reka adegan pada tindakan lain sesuai dengan ketentuan perundang-undangan dan Implementasi terhadap Permenkumham Nomor 33 Tahun 2015 tentang Pengamanan pada Lembaga Pemasyarakatan dan Rumah Tahanan Negara di Lembaga Pemasyarakatan Kuningan belum sepenuhnya diterapkan secara maksimal khususnya dalam hal penjagaan, dimana terdapat kendala berupa belum diisinya semua pos menara atas oleh penjaga dimana yang diisi hanya 1 pos menara atas yaitu pos menara II dan pengawalan pada saat asimilasi tidak dilakukan oleh Satuan Pengamanan tetapi dilakukan oleh petugas staf yang ditunjuk oleh Kepala Lapas. Kurang optimalnya dikarenakan ketidak seimbangan antra petugas lapas dan jumlah narapidana yang sangat banyak sehingga dapam proses nya kurang berjalan dengan baik.

\section{Saran}

Menurut uraian diatas penulis dapat nyimpulkan saran sebagai upaya mencegah terjadinya hambatan pelaksanaan keamanan bagi narapidana di lapas Kuningan dapat dikerjakan melalui penambahan jumlah personil petugas keamanan sehingga antara petugas bagian keamanan dan hunian WBP dilapas dapat sebanding, diperlukannya peningkatan SDM para petugas keamanan Lapas dengan cara memberikan pelatihan- pelatihan khusus yang ada dan juga perekrutan petugas didalam Lapas berdasarkan kemampuan dan keahliannya, supaya dalam bertugas dapat terhindar dari hal-hal yang tidak diinginkan. Diperlukan pula pembatasan terhadap interaksi narapidana dengan dunia luar, Hal ini dilakukan agar ruang gerak narapidana sangat terbatas, sehingga akan sulit untuk melarikan diri. Selain itu, diperlukan peningkatan terhadap kemampuan petugas dalam mengawasi narapidana. Hal terebut sebagai upaya pengoptimalan terhadap implementasi Permenkumham Nomor 33 Tahun 2015.

\section{DAFTAR PUSTAKA}

Ach. Tahir, Cyber Crime (Akar Masalah, SolUSi, dan PenanGGUlangannya), Suka Press, Yogyakarta, 2009. Bambang Poernomo, Pelaksanaan Pidana Penjara dengan Sistem Pemasyarakatan, Liberty, Yogyakarta, 1996.

Barda Nawawi Arief, BUnga Rampai Kebijakan HUKUM Pidana, PT Citra Aditya Bakti, Bandung, 2005.

C. I. Harsono, Sistem BarU Pembinaan Narapidana, Djambatan, Jakarta, 1995.

Departemen Pendidikan Nasional, KamUs Besar Bahasa Indonesia, Gramedia Pustaka Utama, Jakarta, 2014.

Dwidja Priyatno, Sistem Pelaksanaan Pidana Penjara di Indonesia, Bandung, PT Refika Aditama, 2009.

Hadari Nawawi, Metode Penelitian Bidang Sosial, Gajah Mada University Press, Yogyakarta, 2005.

J.T.C. Simontakir dkk, KamUS HUKUm, Sinar Grafika, Jakarta, 2003.

Juhaya S. Praja, Teori HUKUM dan Aplikasinya, CV. Pustaka Setia, Bandung, 2011.

Lexy J. Moleong, Metodologi Penelitian KUAlitatif, Remaja Rosdakarya, Bandung, 2007.

Muhammad Tahir Azhary, Negara HUKUm, Prenada Media, Jakarta, 2003.

Romli Atmasasmita, Sistem Pemasyarakatan di Indonesia, Percetakan Ekonomi, Bandung, 1999.

Soerjono Soekanto, Pengantar Penelitian HUKUM, Universitas Indonesia Press, Jakarta, 2008.

Suharsimi Arukinto, ProsedUR Penelitian: SUaTU Pendekatan Praktek, Rineka Cipta, Jakarta, 2010. 